\title{
DESAIN LEMARI PENYIMPANAN BUKU UNTUK MENUNJANG PROGRAM LITERASI SMAN 6 SAMARINDA
}

\author{
Roni H \\ Staf Pengajar Program Studi Desain Produk, Jurusan Desain \\ Politeknik Negeri Samarinda \\ e-mail: iron_082@yahoo.co.id \\ Septiana Rizky Wulandari \\ Mahasiswa Program Studi Desain Produk, Jurusan Desain \\ Politeknik Negeri Samarinda
}

\begin{abstract}
ABSTRAK
Perancangan dan pengembangan produk inilah yang menjadi suatu bagian dari perubahan abstrak yang ada dalam dunia usaha. Pada ruangan kelas yang berukuran $9 m \times 8 m$ yang akan digunakan untuk meletakkan lemari penyimpanan buku agar kegiatan ini tidak memakan banyak tempat. Lemari penyimpanan buku seperti ini mengharuskan untuk meletakkan buku sesuai dengan ukuran rak-rak yang memang sudah dirancang menggunakan aturan kertas A4. Merancang produk Lemari Penyimpanan Buku dengan menggunakan konsep Adiwiyata yang berarti program lingkungan hidup dengan mengambil warna-warna yang memiliki kesan alami, dan sejuk dan menggunakan gaya desain modern minimalis agar dapat menyesuaiakan dengan ruangan kelas yang tidak terlalu luas. Dengan metode perancangan yang sudah dilakukan antaranya: Tahapan desain, Preliminery desain, Perumusan masalah, Tinjauan pustaka, Analisis dan spesifikasi desain, Spesifikasi desain, Design develoment, Final desain dan prototype. Sehingga dihasilkan desain lemari penyimpanan buku yang memiliki gaya desain modern minimalis.
\end{abstract}

Kata Kunci : Lemari, Penyimpanan, Buku

\begin{abstract}
The design and development of this product is a part of the abstract changes that exist in the business world. In a classroom measuring $9 m \times 8 m$ that will be used to place a book storage cabinet for this activity does not take many places. Book storage cabinets like these require to place books according to the size of the shelves that are already designed using A4 paper rules. Designing a Book Storage Cabinet product using the Adiwiyata concept which means an environmental program by taking colors that have a natural impression, and cool and using a modern minimalist design style to fit the classroom that is not too spacious. With the design methods that have been done include: Design stages, Preliminery design, Problem formulation, Literature review, Analysis and design specifications, Design specifications, Design develoment, Final designs and prototypes. So that a book storage cabinet design has been produced that has a modern minimalist design style.

Keywords: Cupboard, Storage, Books
\end{abstract}


Roni H, Septiana Rizky Wulandari, Desain Lemari Penyimpanan Buku Untuk Menunjang Program Literasi SMAN 6 Samarinda

\section{Pendahuluan}

Lemari buku penting untuk menyimpan, menjaga dan melindungi buku agar buku tidak rusak, sobek, dan berserakan. Lemari penyimpanan buku membantu pembaca untuk memilih buku yang akan dibaca dengan mudah, dan menyimpan buku dengan mudah pada saat tidak digunakan. Lemari buku ini berbentuk seperti persegi panjang. Terdapat juga pengguna yang meletakkan buku di atas meja belajar, di bawah lantai, maupun di atas kasur sehingga buku mudah rusak dan mudah sobek karena terkena benda-benda yang lain.

Bagi SMA Negeri 6 Samarinda yang memiliki berbagai jenis buku tertentu tentang Adiwiyata. SMA Negeri 6 kebingungan dalam menyimpan buku- buku yang banyak karena tidak memiliki tempat yang memadai untuk menyimpan semua bukunya pada setiap kelasnya, sehingga siswa-siswi meletakkan buku di sembarang tempat. Kendala ini yang menyebabkan guru dan siswa-siswi SMA Negeri 6 Samarinda merasa kebingungan pada saat ingin mencari buku yang akan dibaca dan pada saat akan menyimpannya.

Dengan memperhatikan dan mengamati masalah yang sudah dijelaksan di atas, maka diperlukan inovasi pada lemari penyimpanan buku khususnya untuk kebutuhan siswa-siswi SMA Negeri 6 Samarinda. Produk ini difokuskan untuk membuat furniture di dalam kelas. Tujuannya pembuatan produk ink agar siswa-siswi serta guru tidak kesusahan saat memilih dan menyimpan bukunya.

\section{Metode Desain}

Dalam mendesain produk ini, agar terarah menggunakan metode desain dengan langkah-langkah sebagai berikut:

\subsection{Preliminery Desain}

Pengumpulan data dari informasi, analisis data berdasarkan konsep desain makro yang meliputi analisis konsep (konsep fungsi, konsep pemakaian, pemakaian pasar, dan konsep produk), penyusunan program desain sketsa awal. Bagian diatas terdiri dari: 1) Perumusan Masalah,2) Tinjauan Pustaka, 3) Analisis dan Spesifikasi Desain, 4) Spesifikasi Desain.

\subsection{Final Desain dan Prototype}

Dibuat gambar-gambar yaitu gambar presentasi 3D dan gambar teknik (gambar tampak, potongan, gambar detail dan spesifikasi teknik produk). Tahapan selanjutnya adalah pembuatan komponen-komponen dilakukan assembling atau perakitan sehingga menjadi produk (prototype). Bagian ini terdiri dari: Gambar presentasi dalam bentuk 3D modeling, Gambar teknik yang terdiri dari gambar presfektif, gambar tampak, gambar potongan, gambar urai dan gambar detail, Prototipe produk.

\section{Pembahasan \\ 3.1. Analisis Pasar}

Analisis pasar dilakukan guna menentukan sasaran pengguna produk yang akan dirancang. Penentuan target pasar dapat dilakukan berdasarkan pendekatan-pendekatan sebagai berikut :

\section{Segmentasi Demografis}

berdasarkan segmentasi demografis, target pasar produk lemari penyimpanan buku ini akan ditargetkan pada wanita dan pria. Berdasarkan usia, pengguna produk ini berusia 15-17 tahun.

\section{Segmentasi geografis}

Berdasarkan segmentasi geografis, target pasar produk ini dapat dibagi berdasarkan antar sekolah. SMA NEGERI 6 SAMARINDA di Negara Indonesia Provinsi Kalimantan Timur Kota Samarinda ini adalah pemasaran produk tersebut.

\section{Segmentasi psikografis}

Segmentasi psikografi ditujukan pada ruang kelas yang memiliki ruang yang cukup besar sehingga dapat memuat lemari penyimpanan buku untuk menunjang pro- 
Vol. 5, No. 2, April 2018

gram literasi pada SMA NEGERI 6 SAMA-

RINDA.

\subsection{Analisis Ergonomi dan Antropome- tri}

Sasaran penelitian ergonomi adalah manusia pada saat ingin membaca buku, secara singkat dapat dikatakan bahwa ergonomi ialah penyesuaian tugas pekerja dengan kondisi tubuh manusia dengan tujuan kebutuhan sehari-hari yang akan dihadapi, yaitu dengan cara menyesuaikan area ruang belajar dengan dimensi tubuh akan tidak kesulitan.

Antropometri yang akan digunakan untuk menentukan panjang lemari adalah jarak bentang dari ujung jari tangan kanan ke kiri. Gender yang akan digunakan dalam antropometri ini adalah laki-laki dengan percentile yang digunakan adalah $50 \%$ yaitu $1.663 \mathrm{~mm}=1.6$ meter. Jadi panjang lemari yang akan digunakan untuk produk lemari penyimpanan buku ini adalah 1,5 meter.

Antropometri yang akan digunakan untuk menentukan lebar lemari adalah jarak genggaman tangan ke punggung pada posisi tangan ke depan. Gender yang akan digunakan dalam antropometri ini adalah laki-laki dengan percentile yang digunakan adalah $50 \%$ yaitu $708 \mathrm{~mm}=70 \mathrm{~cm}$. Dikarenakan lebar lemari ini guna untuk menaruh buku-buku maka digunakan ukuran yang sesuai dengan ukuran buku yaitu $20 \mathrm{~cm}$ dengan menambahkan tolerani $10 \mathrm{~cm}$ agar buku yang berbentuk landscape dapat masuk. Sehingga total lebar lemari ini adalah $20 \mathrm{~cm}+$ $10 \mathrm{~cm}=30 \mathrm{~cm}$.

Antropometri yang akan digunakan untuk menentukan tinggi lemari adalah Tinggi Pegangan Tangan pada Posisi Tangan Vertikal ke Atas \& Berdiri Tegak. Gender yang akan digunakan dalam antropometri ini adalah laki-laki dengan percentil yang digunakan adalah $50 \%$ yaitu $1.923 \mathrm{~mm}$. Jadi tinggi umum adalah $1.923 \mathrm{~mm}=190 \mathrm{~cm}$. Dengan itu tinggi lemari yang akan digunakan untuk produk lemari penyimpanan buku ini adalah 1,65 meter.

\subsection{Analisis Sistem}

Analisis sistem perlu dilakukan untuk mengetahui sistem-sistem apa saja yang diperlukan pada produk Lemari Penyimpanan Buku untuk Menunjang Program Literasi SMA Negeri 6 Samarinda tersebut.

\section{Sistem Konstruksi Furniture}

Dari analisis sistem yang telah dilakukan, terdapat beberapa jenis konstruksi dan dipilihlah sistem konstruksi Kontemporer yang dinilai memiliki tingkat kekuatan yang baik dibandingkan dengan sistem konstruksi yang lainnya karena lemari penyimpanan buku ini akan menahan beban buku yang berar. Konstruksi kontemporer merupakan sistem konstruksi secara permanen, tak berubah, tidak dibongkar pasang.

\section{Sistem Sambungan}

Dalam produk ini terdapat beberapa komponen yang memerlukan sistem sambungan. Komponen-komponen yang memerlukan sistem sambungan yaitu pada bagian dinding lemari dan rak-rak di dalam lemari yang bertujuan sebagai penyambung satu dengan yang lain.

Dalam menentukan sistem sambungan yang akan dipakai, terdapat beberapa sistem sambungan yang dinilai sesuai untuk diaplikasikan pada produk seperti sistem sambungan butt joint yaitu teknik menyambung dengan membentuk siku, Dove tail housing joints yaitu teknik menyambung dua buah kayu dengan membuat alur pada papan pertama, dan mortise \& tenonyaitu teknik menyambung dengan membuat lidah dan lubang pada bagian kayu. Dalam pemilihan sistem sambungan ini tidak terlepas dari kriteria-kriteria yang telah ditentukan yaitu kemudahan dalam pemasangan, kekuatan sistem sambungan dari setiap sistem sambungan akan mempengaruhi kinerja produk, konsep dari produk seperti pemilihan bentuk dan material yang sesuai dengan sambungan yang digunakan. 
Dari analisis sistem sambungan yang telah dilakukan, dipilihlah jenis sistem sambungan butt joints. Sistem sambungan ini akan diaplikasikan pada seluruh komponen-komponen yang terdapat pada lemari penyimpanan buku. Hal ini dikarenakan sistem ini paling mudah untuk diaplikasikan dalam sebuah produk dan tidak memakan waktu yang cukup lama.

\section{Komponen Hardwares untuk Sambun- gan}

Komponen ini berfungsi untuk memperkuat sistem sambungan yang akan digunakan. Penambahan Hardwares ini bertujuan untuk memperkuat atau sebagai pengunci sistem sambungan yang digunakan dalam produk ini. Terdapat beberapa hardwares yang dapat digunakan untuk menambah kekuatan smabungan seperti sekrup dan paku.

Sekrup dan paku merupakan komponen sambungan yang paling sering digunakan dalam pembuatan suatu produk. Sekrup merupakan besi dengan bentuk memanjang yang memiliki ulir pada bagian pinggirnya, sedangkan paku hanya berupa besi memanjang tanpa memiliki ulir.

Dari kedua komponen ini dilakukan analisis untuk menentukan mana yang akan digunakan dalam pembuatan produk ini. Sebelum melakukan analisis terdpat beberapa kriteria yang telah ditentukan dalam melakukan penilaian yaitu kekuatan, tingkat kemudahan pemasangan, dan harga dari hardwares yang dijual dipasaran serta tingtak kerapian saat dipasangkan pada produk. Dari analisis yang telah dilakukan, dipilihlah komponen sekrup untuk melengkapi sistem sambungan ini. Penggunaan sekrup bertujuan untuk memperkuat sistem sambungan butt joint yang digunakan dan pada saat pembuatan tidak memakan banyak waktu untuk pengerjaan.

\section{Sistem Lipat}

Dari analisis sistem lipat ini, terdapat beberapa komponen yang memer- lukan sistem lipat. Komponen-komponen tersebut adalah daun pintu yang ada pada lemari, agar pintu dapat dibuka dan di tutup. Dalam menerapkan sistem lipat ada beberapa hardwares yang dapat digunakan yaitu engsel kupu-kupu dan engsel lurus.

Engsel kupu-kupu dan engsel lurus ini biasa digunakan dalam pembuatan suatu produk. Untuk memeilih engsel mana yang akan digunakan dalam produk ini dilakukan analisis dengan kriteria yaitu tingkat kerapian, tingkat kekuatan, dan harga engsel yang dijual dipasaran.

Dari analisis yang telah dilakukan diatas, dipilih engsel lurus yang akan diaplikasikan sebagai sistem lipat. Engsel ini merupakan engsel yang sangat umum yang biasa digunakan dalam pembuatan lemari. Keunggulan engsel ini memiliki kerapian yang ba gus dan membuat tampilan akan menjadi rapi.

\subsection{Analisis Material}

Dalam proses pembuatan produk ini metode yang digunakan adalah metode yang menggunakan rangka dan tidak menggunakan rangka. Pada bagian yang menggunakan rangka yaitu bagian atas pada lemari guna untuk menahan beban berat maka metode yang digunakan yaitu metode rangka. Dan metode material yang tidak menggunakan rangka pada bagian badan-badan untuk lemari, karena hanya menggunakan papan yang memiliki ketebalan di atas $9 \mathrm{~mm}$.

\section{Material Rangka}

Analisis material ini dilakukan guna untuk mendapatkan material yang tepat dan cocok digunakan untuk material yang digunakan pada bagian atasan/atap lemari dan untuk bagian lantainya. Dalam proses ini metode yang digunakan adalah material menggunakan rangka, dalam pembuatan produk yang menggunakan rangka ini memiliki kriteria-kriteria yang harus di tentukan, kriteria tersebut antara lain, material yang digunakan mudah untuk di dapat- 
Vol. 5, No. 2, April 2018

kan terutama di Kota Samarinda, harga juga diharapkan cukup terjangkau sehingga mudah untuk dipasarkan, mudah untuk digergaji, mudah untuk dipotong, dan mudah untuk digunakan, dan bahan yang digunakan cukup kuat untuk menahan beban yang akan digunakan.

Dari kriteria yang telah ditentukan di atas, maka di dapatkan material yang akan digunakan yaitu, kayu reng, kaso, dan stainless steel. Dari hasil analisis yang dilakukan, dipilihlah kaso sebagai material yang digunakan untuk rangka pada produk lemari penyimpanan buku, terutama pada bagian atap dan bagian alasnya.

\section{Material Body}

Analisis material ini dilakukan guna untuk mendapatkan material yang tepat dan cocok digunakan untuk Body produk. Dalam proses pembuatan produk ini metode yang digunakan adalah metode tanpa menggunakan rangka. Terdapat beberapa kriteria yang harus ditentukan dalam metode tanpa menggunakan rangka, kriteria-kriteria tersebut antara lain material yang digunakan untuk produk ini diharapkan memiliki ketebalan di atas $9 \mathrm{~mm}$, memiliki konstruksi yang cukup kuat untuk dapat menahan beban berat seperti tumpukan buku-buku, material yang digunakan mudah untuk didapatkan di kota Samarinda, harga juga diharapkan cukup terjangkau sehingga mudah untuk dipasarkan dan mudah untuk diproduksi (seperti, mudah untuk digergaji, mudah untuk di bentuk, mudah untuk di gabungkan dengan komponen yang lain).

Dari kriteria yang telah ditentukan diatas, maka di dapatkan material yang memiliki tebal diatas $9 \mathrm{~mm}$ yaitu, block board, MDF, particle board, dan multipleks. Dari hasil analisis material yang dilakukan, dipilihlah Multipleks sebagai material utama yang akan digunakan dalam pembuatan lemari penyimpanan buku terutama pada seriap bagian-bagian komponen-komponen yang ada pada lemari sehingga dapat terkonstruksi dengan baik dan kuat.

\section{Material Finishing}

Analisis finishing dilakukan guna untuk mendapatkan material finishing apa yang cocok digunakan dalam pembuatan produki lemari penyimpanan buku. Kriteria yang digunakan untuk menentukan material finishing adalah material finishing yang digunakan harus memiliki kesan alami seperti warna yang menyatu dengan alam dengan menggunakan warna-warna yang sejuk, ketahanan material finishing akan goresan dari buku-buku yang diletakkan dalam lemari dan ketersediaan bahan material finishing di kota samarinda dengan harga yang relatif terjangkau.

Dari kriteria tersebut, material yang memenuhi kriteria adalah HPL dan Cat. Dari analisis yang telah dilakukan, dipilihlah material finishing HPL sebagai material finishing utama karena dinilai sangat baik untuk diaplikasikan di produk ini karena memiliki ketahanan yang sesuai dengan konsep pada produk lemari penyimpanan buku.

\subsection{Analisis Bentuk}

Analisis bentuk dilakukan untuk menentukan gaya desain yang sesuai dengan konsep yang akan diaplikasikan pada produk dengan menggunakan tema Adiwiyata. Adiwiyata adalah salah satu program kementrian lingkungan hidup dalam rangka mendorong agar terciptanya pengetahuan dan kesadaran dalam upaya pelestarian alam.

Dari analisis gaya gaya desain yang telah dilaksanakan, dapat disimpukan bahwa gaya desain yang akan digunakan yaitu gaya desain modern dengan gaya desain furniture minimalis.

\subsection{Analisis Warna}

Hasil analisis warna dilakukan guna menentukan warna desain apa yang sesuai dengan konsep yang akan diaplikasikan pada produk dengan menggunakan tema Adiwiyata. Analisis warna dilakukan dalam dua jenis, yaitu untuk warna yang mendominasi dan untuk warna yang digunakan sebagai ak- 
sen. Warna-warna yang kemungkinan besar akan digunakan adalah warna-warna yang memberikan kesan alami, dan sejuk, karena sesuai dengan tema Adiwiyata.

Dari ke empat warna yang memberikan kesan alami ini, warna coklat, biru, dan hijau yang mencangkup kriteria kesan alami dan sejuk, sedangkan warna oranye memberi kesan alami hangat. Maka dari itu warna yang dipilih yaitu hanya warna biru, hijau, dan coklat.Dari ketiga warna itu, yaitu biru, coklat, dan hijau. Warna coklat jika digunakan untuk membaca atau digunakan sebagai tempat meyimpan buku bacaan akan memberikan kesan yang membosankan.

Maka dari itu, warna utama yang akan digunakan untuk membuat produk lemari ini adalah warna biru, karena warna biru merupakan warna yang paling disukai berbagai kalangan termasuk remaja. Karena warna ini memberikan kesan yang sejuk dan alami bagi pengguna dan bagi ruangan yang terdapat furniture yang berwarna biru. Dengan memberikan warna aksen putih agar warna biru terlihat lebih terang dan aura alaminya akan lebih muncul. Sebaliknya jika warna aksen yang diberikan adalah warna hitam, warna lemari yang berwarna dasar biru ditambah dengan warna hitam akan memberikan kesan yang gelap pada ruangan, dan tidak memberikan kesan sejuk dan alami.

Dari hasil analisis diatas, telah ditentukan warna yang akan digunakan yaitu adalah warna biru. Diperkuat hasil analisis dari kuisioner warna ke kelas yang ada di SMA Negeri 6 Samarinda yang terdapat 35 orang siswa-siswi warna yang paling banyak dipilih yaitu warna biru..

\subsection{Pengembangan Desain Desain awal}

Langkah awal dalam mendesain yaitu membuat beberapa sketsa awal desain. Sketsa-sketsa ini selanjutnya dianalisi ssesuai kriteria desain yangbtelah ditentukan. Dari semua alternatif yang telah di analisis, dipilih desain alternative yang ditunjukkan dalam gambar 1. Desain itu dipilih karena memiliki kesan minimalis modern dan mudan untuk diproduksi.

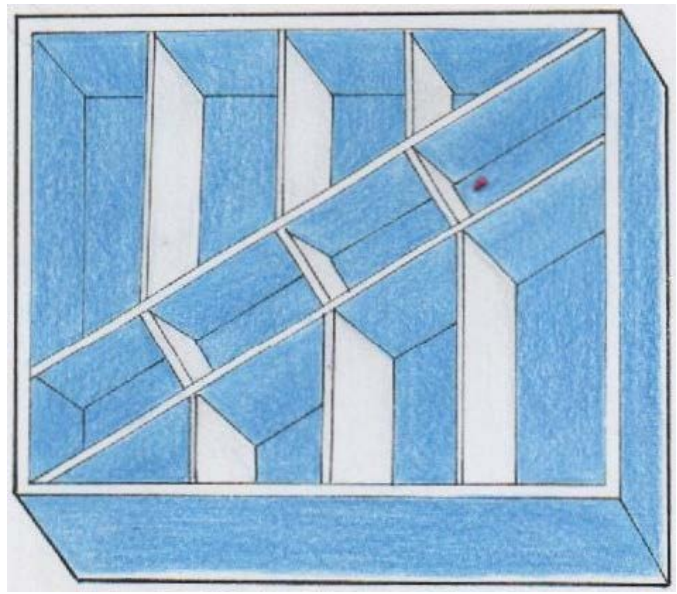

Gambar 1. Desain awal

\section{Pengembangan desain}

Selanjutnya desain terpilih tadi dekembangkan lagi menjadi beberapa alternatif desain, sampai menjadi desain final yang siap untuk diproduksi. Desain final meliputi spesifikasi teknis, lengkap gambar kerja sebagai panduan proses produksi.adapun hasil desain finalditunjukkan dalam gambar 2 .

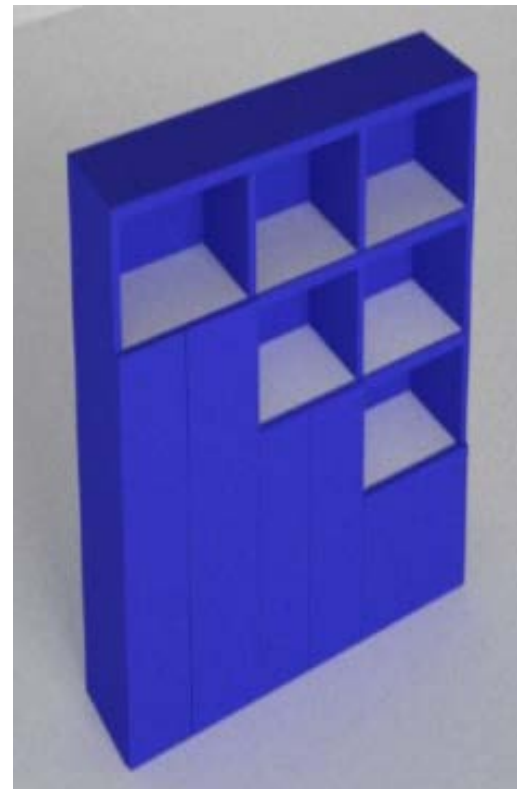

Gambar 2. Desain final 
Vol. 5, No. 2, April 2018

\section{Kesimpulan}

Lemari ini aemiliki tempat penyimpanan untuk berbagai ukuran buku sehingga buku yang akan diletakkan akan terlihat rapi. Warna yang diaplikasikan pada produk yaitu biru dengan memberikan warna putih sebagai warna aksen agar terlihat sejuk dengan menggunakan material finishing HPL.

Saran kelanjutannya agar lebih baik adalah lemari penyimpanan buku ini masih dapat berkembang dengan baik, baik dari sistem, bentuk maupun warna yang digunakan untuk menyelesaikan produk ini. Pembuatan lemari penyimpanan buku ini diharapkan kedepannya dapat mengembangkan produk ini lebih baik lagi dari yang sebelumnya.

\section{DAFTAR PUSTAKA}

Adib, T., \& Drihanto, A (2017). Dazzling Style With Attitude Jakarta : PT Gramedia Pustaka utama. https://www.google.book.co.id/. 23 November 2017.

Akmal, Imelda dkk, (2009). Cermin Interior. Jakarta : PT Gramedia Pustaka Utama. https:// www.google.book.co.id/. 23 November 2017.

Cahyadi, Dwi. (2014). Aplikasi Mannequin Pro untuk Desain Produk. Yogyakarta: LeutikaPrio.

Dumanauw, J, F. (2001). Mengenal Kayu. Yogyakarta : Kanisius. https://www.google. book.co.id/. 23 November 2017.

Erniathi, D, A. (2014). Mengenal Empat Jenis Kayu Olahan Bahan Furniture. Jawa

Timur.

Hardisurya, I. (2004). Warna bagi Citra \& Penampilan. Jakarta : PT. Gaya Favorit Press. https://www.google.book.co.id/. 23 November 2017.

Kasali, Rhenald (1998). Membidik Pasar Indonesia. Jakarta : PT Gramedia Pustaka Utama. https://www.google.book.co.id/. 23 November 2017.

Kotler, P. (2004). Manajemen Pemasaran. Jakarta: PT Indeks Kelompok Gramedia. Marizar, E, S. 2005). Designing Furniture: Teknik Merancang Mebel Kreatif: Konsepsi, Solusi, Inovasi, dan Implementasi. Yogyakarta: Media Pressindo. https://www.google. book.co.id/. 23 November 2017.

Mulyana, D., \& Asmarahman, C. 2010). 7 Jenis Kayu Penghasil Rupiah. Jakarta Selatan: PT AgroMedia Pustaka. https://www.google.book.co.id/. 23 November 2017.

Nita Hidayat, 4 Agustus 2017, Gaya Desain Interior Postmo : Gaya Dekorasi Interior 95

Melabrak sedgala aliran. (Interior desain. Id/gaya-desain-interior-postmodern/)

Sari, N, W. (2010). Ragam Gaya Interior. Jakarta : PT Niaga Swadaya https://www.google. book.co.id/. 20 November 2017.

Tikno, I. (2008). Mengenal Konstruksi Kayu untuk Furniture dan Bangunan. Jakarta: Esensi. https://www.google.book.co.id/. 23 November 2017. 